\title{
EL MITO FUNDACIONAL DE LA HOMEOPATÍA ARGENTINA. LA REVISTA HOMEOPATÍA, BUENOS AIRES (1933-1940)
}

\section{Mg. Manuel A. González Korzeniewski*}

CONICET

\section{RESUMEN}

El presente artículo da cuenta de la construcción identitaria-histórica en la institución de Homeopatía que actualmente es la más importante de la Argentina (y la más antigua de las vigentes). Se construyen dos ejes analíticos: por un lado, la construcción de un mito fundacional que trace un hilo genealógico entre las «divinidades» de la medicina, y por otro, la mitificación de la figura de Hahnemann, padre fundador de la disciplina. A través de ambos ejes se explica cómo los discursos de la revista creaban un sostén simbólico para la débil coyuntura en la que se procuran consolidar legalmente como institución.

PALABRAS CLAVE: Homeopatía. Legitimación. Mito fundacional. Discursos.

\section{THE FOUNDATIONAL MYTH OF ARGENTINIAN HOMEOPATHY. THE JOURNAL HOMEOPATÍA, BUENOS AIRES (1933-1940)}

\begin{abstract}
The present article analyzes the historical-identitary construction in the older and most important institution of Homeopathy in Argentina. Two analytical axes are constructed: on the one hand, the construction of a foundational myth that outlines a genealogical thread between the «divinities» of the medicine, and on the other hand, the mitification of Hahnemann, founding father of the discipline. Using both axes we explain how the discourses of the journal were creating a symbolic support for the weak conjuncture in which they tried to be consolidated legally as an institution.
\end{abstract}

KEY WORDS: Homeopathy. Legitimacy. Foundational myth. Discourses.

* Magíster en Ciencia, Tecnología y Sociedad (UNQ), becario doctoral del Consejo Nacional de Investigaciones Científicas y Técnicas (CONICET), Argentina. Instituto de Estudios Sociales de la Ciencia y la Tecnología (IEC), Universidad Nacional de Quilmes (UNQ). Email: mangonzalez@unq.edu.ar. 


\section{INTRODUCCIÓN}

Este artículo da cuenta de cómo se construyó una identidad histórica en la actual Asociación Médica Homeopática Argentina (AMHA, creada en principio como Sociedad - SMHA) durante su primera década de vida, la de 1930. Considerando que no existían instituciones homeopáticas hasta entonces en Argentina (a excepción de dos intentos fugaces en el último cuarto del siglo XIX) los fundadores de la AMHA debieron consolidar su posición definiendo los principios y alcances de su práctica.

Esta construcción se analiza en torno a dos ejes: por un lado, la creación de un mito fundacional que da explicación de la coyuntura y legitima la aparición de este saber médico en una época determinada; por otro lado, la narración sobre la vida y obra de Christian Samuel Hahnemann, en clave mítica, que inserta al padre fundador de la homeopatía en el hilo metafísico y genealógico de los «maestros» de la medicina.

A continuación se definen de manera sucinta los principios de análisis que sirvieron para la interpretación y construcción de los dos ejes de este trabajo; en segundo lugar se presenta, también brevemente, el contexto social y médico de la década de 1930; en tercer lugar se desarrolla el primero de los ejes de análisis: el mito fundacional de la homeopatía argentina; en cuarto lugar, el segundo eje: la mitificación de Hahnemann; y por último, las conclusiones.

\section{INSTITUCIÓN Y MITOLOGÍA}

Los ejes expuestos antes son dos de los múltiples caminos posibles a partir de los cuales analizar los textos de la revista Homeopatía en dicha época ${ }^{1}$. Ambos parten de la idea de que las instituciones tienen como fin consagrarse como legítimas para instituir a alguien o algo con ciertos atributos, estatus o propiedades: «basta con reunir las distintas acepciones de instituere y de institutio para obtener la idea de un acto inaugural de constitución, de fundación,

1 Otros ejes fueron analizados en GonZÁLEz KorZENIEWSKI, M. (2008), Status científico, discursos y conflictos: El proceso de institucionalización de la homeopatía argentina. La revista Homeopatía, Buenos Aires, 1933-1940, tesis de maestría en Ciencia, Tecnología y Sociedad, BERNAL, UNQ: Crítica y construcción homeopática de la Alopatía: nociones contrapuestas de salud y enfermedad; concepción de enfermos, pacientes y clientes; lo moderno y lo arcaico, entre otros. 
incluso de invención, que conduce por medio de la educación a disposiciones duraderas, a costumbres, a usos» $»^{2}$.

La institución de una identidad «es la imposición de una esencia social. Instituir, asignar una esencia, una competencia, es imponer un derecho de ser que es un deber ser (o de ser). Es notificar a alguien lo que es y notificarle que tiene que comportarse en consecuencia» ${ }^{3}$. En el caso que se presenta en este artículo, los actores debieron esforzarse por dejar claro qué era y qué no era la homeopatía, cuáles eran los alcances, los límites de la disciplina y debieron establecer esa «frontera mágica».

La utilización de los análisis de los mitos permite indagar en el discurso homeopático de la época la aparición de algunos elementos constitutivos de la práctica homeopática. Para Lévi Strauss, el mito otorga un origen a algunas cosas del presente, y al acentuar ese origen, le da más relevancia y también produce un pasado. Así, lo que tiene pasado, reclama en el presente una legitimidad igual y proyecta esta estructura hacia el futuro ${ }^{4}$; ahora bien ¿es válido utilizar la idea de «mito» como punto de partida para estudiar la institucionalización de una disciplina científica (o que se pretende como tal)? El autor sostiene que «en nuestras sociedades la historia sustituye a la mitología y desempeña la misma función [...] a pesar de todo el muro que existe en cierta medida en nuestra mente entre mitología e historia probablemente pueda comenzar a abrirse a través del estudio de historias concebidas no ya en forma separada de la mitología, sino como continuación de ésta» ${ }^{5}$.

El discurso de la revista Homeopatía durante aquellos años fundacionales, tiene la particularidad de corresponderse con la siguiente caracterización de los mitos de origen:

1. «Describen las diversas, y a veces dramáticas, irrupciones de lo sagrado (o de lo "sobrenatural") en el Mundo».

2 Bourdieu, P. (1993), Los ritos como actos de institución. En PitT-Rivers, J.y PerisTANY, J.G. (eds.), Honor y gracia, Madrid, Alianza, pp. 111-123.

3 BouRdieU (1993), p. 117.

4 Para Mircea Eliade, resulta muy difícil llegar a una definición de mito que abarque todas las concepciones del mismo. Es de interés en este trabajo la siguiente definición «es, pues, siempre el relato de una "creación": se narra cómo algo ha sido producido, ha comenzado a ser [...] Los personajes de los mitos son seres sobrenaturales. Se les conoce sobre todo por lo que han hecho en el tiempo prestigioso de los “comienzos"». EliAdE, M. (1992), Mito y realidad, Barcelona, Labor, p. 12.

5 LÉvi Strauss, C. (1995), Mito y significado, Madrid-Buenos Aires, Alianza, p. 65. 
2. «Se considera como una historia sagrada y, por tanto, "verdadera", puesto que se refiere siempre a realidades».

3. «Se convierte en el modelo ejemplar de todas las actividades humanas significativas».

4. No sólo relatan el origen del Mundo «sino también todos los acontecimientos primordiales a consecuencia de los cuales el hombre ha llegado a ser lo que es hoy».

5. Se comunica a los neófitos durante su iniciación, «se "celebran", es decir, se les reactualiza» ${ }^{6}$.

Se trata de poner de relieve de qué manera aquellos homeópatas justificaban su irrupción en la vida social remontándose a la "pureza de otros tiempos»: así el mito de origen, es una continuación del mito de la creación, «rememora brevemente los momentos esenciales de la Creación del Mundo, para pasar a narrar a continuación la genealogía de la familia real, o la historia tribal, o la historia del origen de las enfermedades y de sus remedios, y así sucesivamente $[\ldots]$ es la reactualización del comienzo absoluto» ${ }^{7}$.

Se reinvindica aquí el supuesto de que a través del discurso se pueden construir materialidades, causalidades y evidencias concretas partiendo de considerar el lenguaje, los discursos, como prácticas sociales y no como una mera «expresión» o «representación» y que como «toda práctica del sujeto se produce siempre en una situación social que le impone unos imperativos prácticos, materiales y simbólicos $»^{8}$. La idea, entonces, es entender el discurso que aparece en la revista Homeopatía como una práctica concreta inserta en un contexto histórico y susceptible de ser analizada con los principios de análisis antes enunciados.

\section{CONTEXTO HISTÓRICO, SOCIAL Y MÉDICO}

La década de 1930 en Argentina es un período de crisis que se expresa en distintos planos como el político, militar y económico, de pujas constantes entre distintos sectores por la detentación del poder a diferentes niveles y durante la cual se quiebra con el orden «liberal» establecido en las décadas precedentes. Toda la vida social de la época se ve afectada por estos hechos y,

6 Eliade (1992), pp. 12-21.

7 ELIADE (1992), pp. 43-44.

8 Martín Criado, E. (1998), Los decires y los haceres, Papers, 56, pp. 57-71. 
lejos de permanecer ajenos, los sectores intelectuales y la disciplina médica se ven interpenetrados por esta problemática general.

El desencadenamiento de la crisis se atribuye a la caída de la «articulación entre sociedad civil, sistema político y aparato estatal, que se implantara con relativa eficacia a partir de $1880 »{ }^{9}$. El lapso entre 1880 y la crisis de 1930 coincide, aproximadamente, con el período de desaparición de las instituciones homeopáticas del siglo XIX y la reaparición en 1933, y con la consolidación del poder médico de las facultades de medicina, firmemente alopáticas.

La Buenos Aires de 1920 y 1930 se caracteriza por una «cultura de mezcla», un cosmopolitismo propiciado por el aumento considerable de población (de 677.000, en 1895, pasando por 1.576.000 habitantes en 1914, a 2.415.000 en 1936) gracias a la llegada de inmigrantes, que transforman las necesidades de atención médica hacia formas organizadas y hospitalarias, dejando de lado la atención de consultorio y pasando a ser del interés del Estado: «La medicina deja de ser un asunto privado, principalmente privado, para entrar briosamente en el campo de lo público. La salud, si es individual, es también un fenómeno eminentemente de interés colectivo y público» ${ }^{10}$.

Esa situación coincide además con un período de «modernización» de la ciudad (por ejemplo, implementación de luz eléctrica, utilización de medios colectivos de transporte, asfaltado, aumento en la tirada de las publicaciones, llegada e implementación de novedosos artefactos técnicos) y la producción intelectual ${ }^{11}$ :

Se trata de un período de incertidumbres pero también de seguridades muy fuertes, de relecturas del pasado y utopías, donde la representación del futuro y la de la historia chocan en los textos y las polémicas. La cultura de Buenos Aires estaba tensionada por «lo nuevo», aunque también se lamentara el curso irreparable de los cambios [...] La Modernidad es un escenario de pérdida pero también de fantasías reparadoras. El futuro era hoy ${ }^{12}$.

9 Belmartino, S., Bloch, C., Persello, A. y Carnino, M. (1988), Corporación médica y poder en salud; Argentina, 1920-1945, Buenos Aires, OPS, p. 14.

10 Boletín de la federación gremial Médica de la provincia de Santa Fe (1936), extraído de Belmartino, Bloch, Persello y Carnino (1988), p. 11.

11 Véanse: Romero, J.L. (2004), Latinoamérica. Las ciudades y las ideas, Buenos Aires, Siglo XXI; SARLo, B. (1988), Una modernidad periférica: Buenos Aires, 1920 y 1930, Buenos Aires, Nueva Visión; SARLo, B. (1992), La imaginación técnica. Sueños Modernos de la cultura argentina, Buenos Aires, Nueva Visión.

12 SARLO (1988), p. 19. 
Lo que ocurre, argumenta Sarlo, es que «las relaciones mediatizadas propias de una sociedad moderna [...] transforman ámbitos antes familiares y gobernables, descentran sistemas de relaciones que parecían estabilizados desde y para siempre» ${ }^{13}$. La elite local miraba hacia Europa, en especial a Francia como un faro de la civilización, al tiempo que sólo aquellos profesionales que lograban demostrar éxito en Europa eran reconocidos por el establishment médico de nuestro país. La referencia era la cultura francesa «desde el punto de vista intelectual» ${ }^{14}$, además, a partir del siglo XX «se verificó un creciente interés por parte de los intelectuales latinoamericanos hacia corrientes filosóficas de origen europeo continental, alejadas del positivismo, que había sido la corriente hegemónica de pensamiento desde las últimas décadas del siglo $\mathrm{XIX} \gg^{15}$.

Al mismo tiempo, «coexisten elementos defensivos y residuales junto a los programas renovadores, rasgos culturales de la formación criolla al mismo tiempo que un proceso descomunal de importación de bienes, discursos y prácticas simbólicas» ${ }^{16}$. Todo este tipo de intromisiones genera un «malestar» en la intelectualidad, y particularmente en la élite médica, que habla de una crisis ética, producto de la corrupción de valores, señalada a nivel general de la sociedad, pero también a nivel universitario: «El exceso de tecnicismo y maquinismo nos ha sumido en un avaro egoísmo sin Dios» ${ }^{17}$.

La inserción de implementos técnicos novedosos que llegan a la cultura de Buenos Aires, abre toda una nueva dimensión imaginaria y reconfigura relaciones simbólicas con mitos y objetos del pasado:

No hay razón para no creer que todo puede ser posible: la rapidez con que ciertas modificaciones técnicas se incorporan en el horizonte de la vida cotidiana refuerza la idea de milagro, que inspira metáforas bien conocidas: el milagro de la electricidad, el milagro de la radio, el milagro del cine [...] cuando sonidos e imágenes se difunden por conductos invisibles e inmateriales, todo un sistema de equivalencias puede edificarse a propósito de otras transmisiones y recepciones a distancia $^{18}$.

\footnotetext{
13 SARLo (1988), p. 32.

14 Plotkin, M. (2003), Freud en las pampas, Buenos Aires, Sudamericana, p. 31.

15 PlotKin (2003), p. 36.

16 SARLO (1988), p. 28.

17 Bullrich, J. (1934), Discurso de inauguración de los cursos de la Facultad de Medicina en 1934, citado en Belmartino, Bloch, Persello y CARnino (1988), p. 17.

18 SARLO (1988), pp. 135-136.
} 
Así se asienta la particular manera de asimilación de lo novedoso, una fusión de artefactos y explicaciones «inverosímiles» con la cultura tradicional:

\begin{abstract}
Viejas obsesiones de la cultura tradicional (desde el cuento de «aparecidos» hasta el curanderismo de la campaña) encuentran un nuevo discurso urbano en la teosofía, la parapsicología y la difusión de nociones psicológicas e, incluso, psicoanalíticas. Una mitología nueva, que usa discrecionalmente un léxico que evoca a la ciencia, traduce obsesiones tan permanentes como la comunicación con el más allá, la vida después de la muerte, la fuente de la eterna juventud, el deseo de curas milagrosas y la transmisión del pensamiento ${ }^{19}$.
\end{abstract}

Frente al contexto cambiante y crítico, los médicos construyen miradas sobre el pasado, presente y futuro, y convocan a la unidad, a la organización y al gremialismo como forma de lucha o defensa, frente a una vida social compleja que influye sobre el desarrollo, hasta entonces rutinario, de la profesión médica.

Hubo varios intentos de concretar el gremialismo médico, pero recién en la década de 1920 surgen las primeras instituciones «perdurables». Los problemas a los que se enfrentan los médicos por entonces son múltiples, causando «malestar» ${ }^{20}$, y cuyas «formulaciones no siempre son claras, los excesos retóricos, frecuentes, las contradicciones no faltan, así como tampoco las identificaciones mecánicas con procesos ocurridos en otras esferas o con situaciones - bien o mal conocidas - existentes en otros países ${ }^{21}$. Como ya se señaló, la cultura de Buenos Aires miraba por entonces a Francia como ideal de cultura, donde paralelamente se da un "auge de los enfoques llamados holistas» ${ }^{22}$.

George Weisz habla de la década de 1930 como un período de crisis y reconfiguraciones de la medicina francesa: «las nuevas perspectivas de la patología funcional parecían echar agua al molino de la tendencia holista. La endocrinología y la inmunología, por ejemplo, insistían en un enfoque sistémico: no se hacía hincapié en el agente causal de las enfermedades sino en las capacidades del cuerpo para responder a estos agentes», además de que el fuerte aumento del número de médicos (de 15.000 en 1890 a 25.000 en 1936) los indujo a «desarrollar unas prácticas originales atractivas para los pacientes» ${ }^{23}$.

19 SARlo (1992), p. 135.

20 Caracterización desarrollada por Belmartino, Bloch, Persello y CARNino (1988), a partir de la revisión de los discursos médicos de la época.

21 Belmartino, Bloch, Persello y Carnino (1988), p. 16.

22 Weisz, G. (1998), Un período de auge: la crisis de los años treinta, Mundo Científico, $\mathrm{n}^{\mathrm{o}} 193$, septiembre, p. 42.

23 WEISZ (1998), pp. 42-46. 
Al mismo tiempo, en Buenos Aires los médicos tenían una autopercepción de su trabajo como «un ejercicio profesional insatisfactorio, escasamente retribuido, crecientemente mercantilizado, que en ocasiones se desliza hacia prácticas reñidas con principios éticos de aceptación generalizada» ${ }^{24}$. De todos modos, la perspectiva no es pesimista universalmente ya que en los discursos médicos de la época hay una importante presencia de voluntad transformadora, que apela a que una «élite» dirija, según los valores tradicionales, a la profesión de la «inquietud»y el «inmoralismo» al «orden» y la «moral».

Otro de los órdenes que se ve afectado, el de la atención particular, se relaciona a un orden capitalista general, según el cual la libre competencia industrial por la que los pequeños artesanos pierden espacio ante las grandes industrias, se traslada a la profesión médica. Por lo tanto, los médicos particulares perderían posibilidades económicas ante los grandes centros asistenciales. Esta dificultad aparece relacionada, como se percibe en las líneas anteriores, con que el fenómeno de masificación en las aulas trasladado al de profesionales.

Este fenómeno es cuantificado en numerosas oportunidades: por un lado, se habla de 6.500 médicos en todo el territorio nacional, para diez millones de habitantes en 1930 (1.523 habitantes por médico ${ }^{25}$, mientras que el Censo de 1934 señala 9.600 médicos para doce millones de habitantes $(1.250$ habitantes por médico). En 1944, presuntamente había 13.924 médicos para catorce millones de habitantes (1.010 habitantes por médico) ${ }^{26}$. La mayor concentración de médicos, además, se da en Buenos Aires; a mediados de la década de 1930 la tasa es de seiscientos habitantes por médico, y para 1944, hay cuatrocientos habitantes por profesional.

En suma, la profesión médica se ve signada por el nacimiento de nuevas especialidades y corporaciones; la definición de un área específica de eficacia técnica; el vínculo entre las necesidades de la población y la capacidad de intervención de los profesionales; en el reconocimiento social de la eficacia de la práctica y, por lo tanto, en el necesario contralor de aquellas acciones; en la búsqueda de formas organizativas que permitan defender los intereses profesionales ante el estado u otras instituciones; en las relaciones con el Es-

24 Belmartino, Bloch, Persello y Carnino (1988), p. 20.

25 Boero, E. (1931), Discurso pronunciado en el aniversario del Colegio de Médicos de la Capital Federal, Rev. Cir. Med. Sud., 49 (10), feb de 1931, citado por Belmartino, Bloch, Persello y CARNino (1988), p. 20.

26 ARCE, J. (1944), Asistencia médica y seguridad social. Ensayo de organización de la asistencia médica para todos los habitantes de la Nación Argentina, S.M., LI (36), pp. 478495, citado por Belmartino, Bloch, Persello y Carnino (1988), p. 21. 
tado, en tanto garante del derecho de la profesión a reclamar un ámbito exclusivo de práctica poseedor de la capacidad jurídica para definir los límites de dicho campo; en su capacidad para intervenir como regulador de los mecanismos del mercado, o para establecer servicios o instituciones financiadoras que desvinculen la práctica profesional de estos mecanismos; $\mathrm{y}$, finalmente, como núcleo crecientemente visible de una red más o menos estable de relaciones de poder en la cual la profesión procura insertarse.

Además, existía una puja por la legitimidad social con curanderos, manosantas y herboristas, lo cual se manifiesta en evaluaciones y propuestas de solución por parte de distintas instituciones médicas «se analizan la legislación represora y los procedimientos destinados a aplicarla, se formulan denuncias y, más allá del constante reclamo de una más eficaz acción de los organismos estatales, se procura dilucidar las causas de la aceptación popular de la actividad de tales curadores y, a partir de ellas, las posibles acciones destinadas a modificar la situación $»^{27}$. Pero «poco pesan los desmentidos y las denuncias frente al deseo de creer que se está a un paso de la panacea universal» ${ }^{28}$.

En este contexto, la propuesta homeopática buscaba diferenciarse de otras terapias «alternativas» basándose en sus principios:

1. Ley de semejanza o similitud: la acción curativa de una droga está dada por poder producir en el hombre sano aquello que a su vez es capaz de curar en el enfermo.

2. Experimentación en el hombre sano: La única manera posible de averiguar su poder medicinal es observando los cambios que los medicamentos pueden producir en el organismo sano; estos cambios son los indicios de su acción curativa homeopática, puesto que revelan su poder para extinguir curativamente síntomas semejantes que se presentan en las enfermedades naturales.

3. Dosis infinitesimales/sucusión (sacudir vigorosamente): al experimentar con sustancias en bruto se observaba muchas veces fenómenos tóxicos, por lo cual Hahnemann decisión diluir las sustancias. Al mismo tiempo, para una mejor mezcla del soluto con el solvente, sacudía las diluciones, atribuyendo acción terapéutica a ambas operaciones.

4. Remedio único: para cada uno debe existir una «patogenesia» (tipificación de «persona enferma») y para cada una de ellas hay un medicamento homeopático único que puede reestablecer la energía vital.

27 Belmartino, Bloch, Persello y Carnino (1988), p. 36.

28 SARLO (1992), p. 152. 
Por su parte, las principales críticas de la «alopatía», específicamente contra la Homeopatía, estaban fundamentalmente encarnadas en el Departamento Nacional de Higiene y en su Dirección de farmacia y pueden resumirse en los siguientes ítems:

1. Que las Facultades de Medicina «no incluían en el plan de enseñanza el estudio del tratamiento de las enfermedades por el sistema homeopático»» y «tampoco la Farmacopea Argentina lo contempla».

2. Que cada «enfermedad para la homeopatía resulta de un cambio invisible producido en el cuerpo humano por una potencia morbífica natural», lo cual prescinde «de todo conocimiento de la economía humana».

3. «Los medicamentos se emplean a dosis infinitesimales, de imposible identificación, porque no responde a los reactivos más sensibles, siendo imposible por consiguiente, comprobar en cada caso si se administra substancia medicamentosa o simplemente agua y azúcar»».

4. Las pretendidas acciones de este sistema curativo no son más que los fenómenos naturales de la enfermedad, interpretados por los que no los conocen [...] a la supuesta acción dinámica del medicamento. Las dosis administradas no tienen acción alguna sobre el organismo del enfermo. Es así que la Homeopatía se reduce solamente al hacer medicina expectante y sugestiva.

5. No interesa tanto la entidad mórbida como el síntoma, no interesa la causa, no interesa la anatomía patológica, no interesa la fisiopatología, no interesa la bacteriología; en suma, se prescinde de las conquistas inconmovibles de la medicina. No es, pues, una ciencia, es una simple hipótesis que no tiene razón de ser, puesto que las hipótesis sirven mientras los hechos no han sido demostrados [...] la analogía entre los síntomas medicamentosos y los consecutivos a lesiones de órganos, no existe en patología ${ }^{29}$.

Otra de las cuestiones destacables en discusión era la expansión de la homeopatía a nivel internacional. Si de un lado los homeópatas afirmaban que la terapéutica estaba en franca expansión, del otro los alópatas sostenían que estaba recorriendo el camino inverso.

El Departamento Nacional de Higiene sostenía que «a pesar del largo tiempo que llevan emitidas, las ideas de la homeopatía sólo son aceptadas por

29 Departamento Nacional de Higiene (1937), Informe, Homeopatía, (1940), VII (912), 266-273, pp. 266-267. 
escasa cantidad de médicos» ${ }^{30}$. En respuesta a ello, los homeópatas, afirmaban que su terapéutica representa «una ciencia conocida universalmente y de amplia divulgación y aplicación en países que marchan a la cabeza de la civilización, como Inglaterra, Francia, Estados Unidos de Norteamérica, Alemania, Italia, España, etc.» ${ }^{31}$.

La relación de la SMHA con el exterior se ve reflejada en el intercambio por canje de revistas bastante frecuente con Europa, fundamentalmente con Francia, y en los reportes anuales de los congresos de la Liga Homeopática Internacional (fundada en 1925 en Países Bajos para la propagación de la terapéutica) que iban realizando: en 1934 en los Países Bajos ${ }^{32}$; en 1935 Godofredo Jonás, presidente de la SMHA, viaja al congreso de Budapest que «congregó alrededor de 150 médicos representantes de más de 20 naciones» ${ }^{33}$; en 1936 se realiza un congreso en Glasgow, al que no asiste ningún médico argentino y no se le otorga mayor importancia.

Ése año se publica un artículo sobre el «Estado actual de la Homeopatía en el mundo» que contiene descripciones y numerosas fotografías de instituciones y publicaciones de más de treinta países, con especial detalle en la «cuna de la homeopatía», Alemania (400 médicos y decenas de instituciones); el país con «mayor desarrollo», EE.UU. (10.000 médicos, 101 hospitales homeopáticos «acreditados» y más de 200 «afiliados»); Inglaterra (más de 200 médicos, 13 hospitales) y la ciudad de París (1900 médicos, 4 hospitales y 12 dispensarios) ${ }^{34}$. Se reseña que en España, antes de la guerra, «habían unos 200 médicos» ${ }^{35}$.

En 1937 se realiza el congreso en Berlín, «uno de los más numerosos que se hayan llevado a cabo hasta la fecha» y patrocinado por «el gobierno del Reich», según el Dr. Francisco Monzo, representante argentino ${ }^{36}$. A su regre-

30 Departamento Nacional de Higiene (1937), p. 273.

31 JonÁs, G. y SEMich, R. (1937), Respuesta de la Sociedad Médica Homeopática Argentina al informe del D. N. de Higiene, Homeopatía, VII (9-12), 273-290, p. 274.

32 Vinyals, A. (1934), Congreso Homeopático Internacional. Celebrado en Arnhem (Holanda) en 25 a 28 de julio de 1934, Homeopatía, I (9-10), 308-319 [originalmente aparecida en El Sol de Meissen, de Barcelona].

33 SMHA (1935), Actividades, Homeopatía, II (9-10), pp. 249-250.

34 Deveze, M. (1936), Estado actual de la homeopatía en el mundo, Homeopatía, III (1011-12), 317-362.

35 DeVEZE (1936), p. 324.

36 Para dar muestras del apoyo oficial al congreso, Monzo señala también que asistió al congreso el «señor Rodolfo Hess, representante del "Fuehrer" y ministro del Reich», el «Director General de Sanidad», el «Jefe del Cuerpo de Farmacéuticos del Reich» y «autoridades 
so, Monzo visitó la ciudad de Río de Janeiro, donde estableció fuertes vínculos con el Instituto Hahnemanniano del Brasil, conociendo además a las autoridades de la revista Voz Homeopática, la Facultad de Medicina Homeopática y el Hospital Homeopático ${ }^{37}$.

Al año siguiente, se realizó el congreso en Niza de 1938, sin representantes argentinos. Ya en 1939, y naturalmente en los años subsiguientes, no se hace referencia a congresos europeos, con lo cual empiezan a tomar mayor importancia los lazos con las sociedades americanas. Es así que se logra un importante contacto con el congreso panamericano, con médicos de México y EE.UU ${ }^{38}$.

En 1939, en pleno conflicto por la legalización de la SMHA a nivel estatal, las embajadas argentinas en EE.UU. ${ }^{39}$ y Alemania ${ }^{40}$ remiten informes favorables a la Homeopatía, ya que indican formación y atención legal en Estados Unidos y Alemania, así como legislación específica para los fármacos en este último.

\section{LA FUNDACIÓN Y EL MITO FUNDACIONAL}

Luego de los intentos de institucionalización de la homeopatía en el último cuarto del siglo XIX, todo tipo de intentos asociacionistas desaparecen hasta que, según consta en distintas publicaciones históricas de los propios homeópatas $^{41}$, tras varias décadas de esfuerzos individuales, nueve profesionales de

de la ciudad de Berlín». Monzo, F. (1937), XII Congreso Internacional de Homeopatía en Berlín, Homeopatía, IV (11), 289-305, p. 297.

37 MONZO (1937), p. 303.

38 Gacetilla del Congreso Pan Americano (1939), Homeopatía, Vi (6), 206-210.

39 Informe de la Embajada ARgentina en WASHington (1940), Homeopatía, VII (912), p. 291.

40 INFORME DEL MiNiSTERIO DE RELACIONES EXTERIORES DE AlEMANIA A LA EMBAJADA Argentina (1940), Homeopatía, VII (9-12), p. 292.

41 La versión original es dada a conocer por Jonás en Homeopatía, en diciembre de 1936 (JoNÁs, G. (1936a), La Homeopatía en la República Argentina. Notas históricas y de actualidad, Homeopatía, III (10-11-12), pp. 308-316) y republicada veinte años después por la misma revista. Dicha reedición es citada por distintos autores y constituye la referencia más habitual en la materia. Ver, por ejemplo, KAUFMANN, E. (2004), Historia de las Escuelas Médicas, en AMHA (comp.), Tratado de Doctrina Médica Homeopática, Buenos Aires, Editorial de la AMHA, pp. 15-30; GONZÁLEZ LEANDRI, R. (1997), La construcción histórica de una profesión. Asociaciones e instituciones médicas en Buenos Aires: 1852-1895, Tesis doctoral, Universidad Complutense de Madrid. 
la medicina homeopática se reúnen en la «Confitería del Molino» del centro porteño, el 22 de julio de 1933 y deciden crear una Sociedad que los nucleara ${ }^{42}$.

La Sociedad Médica Homeopática Argentina ${ }^{43}$ tuvo como primer presidente a Godofredo Jonás ${ }^{44}$, vicepresidente Armando Grosso, Rodolfo Semich secretario, Eugenio Anselmi tesorero y como vocales a Enrique Bonicel, Francisco Monzo y Tomás Paschero ${ }^{45}$. Todos ellos fueron médicos recibidos en Universidades Nacionales, a excepción de Enrique Bonicel, que era farmacéutico francés llegado a principios de la década de 1930. En pocos años, Bonicel ayudó en la formación de algunos de ellos, como Grosso y Paschero, y logró reunirlos con Jonás, Jorge Masi Elizalde y Carlos Fisch, quienes aisladamente practicaban la homeopatía y la habían aprendido en forma autodidacta.

La Sociedad comienza a funcionar a través de sucesivas reuniones que incluyen una serie de conferencias de algunos de los médicos fundadores. En dichas reuniones además de gestarse el propio lanzamiento de la revista Homeopatia, se puede percibir un esfuerzo manifiesto por construir un mito fundacional, que diera cuenta del surgimiento de la institución local y que luego ocupara buena parte de las páginas de la revista (sobre todo en los primeros tiempos).

La revista Homeopatía fue impresa por primera vez sólo medio año después de la fundación de la SMHA, en enero de 1934, con la «doble finalidad perseguida: en primer término, la Revista debe ser el portavoz de los médicos homeópatas y su órgano de publicidad científica; en segundo lugar, también servirá para los demás colegas que no han tenido oportunidad de conocer los fundamentos teóricos de la admirable Materia Médica Homeopática» ${ }^{46}$.

Posteriormente se hace mención a «bosquejos históricos» lo cual indica la necesidad de formar a un lector recién iniciado o ajeno a la homeopatía, resaltado en el desarrollo «sencillo» y «didáctico» con el que se intentará dar a conocer. Se anuncia la publicación de las «obras más autorizadas», un rasgo que coincide con lo «doctrinario» de la disciplina y con parte de la formación institucional de generar un escalafón. De esta manera, explícitamente los edi-

42 JonÁs, G. (1934a), Conferencia en la inauguración del local de la SMHA, Homeopatía, I (11-12) p. 343-346.

43 Posteriormente adoptaría el nombre de Asociación Médica Homeopática Argentina, que conserva hasta la actualidad.

44 Nieto de E. Jonás, abogado y homeópata autodidacta, quien tuvo una «destacada labor en la epidemia de fiebre amarilla de fines de siglo XIX», JONÁS, (1936a).

45 JONÁs (1934a).

46 Semich, R. (1936), Dos años de labor, Homeopatía, III (1-2), pp. 1-2. 
tores se proponen hacer pública una jerarquía de la homeopatía a nivel nacional (quien pronuncia las conferencias, quien comenta las obras) y otra a nivel disciplinario general (qué obras leer, en qué orden).

El alcance de la revista, por los escasos datos que se pueden recabar, es de un promedio de 70 ventas al mes aproximadamente (a lo que habría que sumarle un indeterminado número de canjes y donaciones), siendo su impresión deficitaria en relación a los ingresos recibidos por venta ${ }^{47}$.

Al cumplirse un año de la fundación institucional, se publica un número de Homeopatía dedicado exclusivamente a conferencias realizadas en la sede. Así se reseñaba un balance del primer año de vida:

[...] hemos trabajado intensamente en pro de la difusión de nuestras doctrinas médicas y en muchos profesionales ha despertado legítimo y vivo interés el estudio de la Homeopatía. Lo comprobamos en las reuniones de la Sociedad, cada vez más concurridas; en la atención preferente que se presta a las comunicaciones presentadas; en las consultas frecuentes que los colegas nos hacen al solicitar informes acerca de multitud de cuestiones clínicas y terapéuticas. Y bien sabemos que no suele haber error en este pronóstico: el médico que se interesa por la Homeopatía —a veces el que comienza como simple curioso-, en virtud de la gravitación que ejercen las grandes ideas y los hechos claros, concluye, fatalmente, por ser homeópata ${ }^{48}$.

Aquí aparecen algunos rasgos que permiten entender que sentido le atribuían a su rol social estos médicos, la de pioneros en un terreno hostil:

[...] necesitamos llenar la función social que nos impone la condición de médicos en modo que mejore la capacidad técnica de que debemos estar dotados ${ }^{49}$.

La iniciación fue difícil. La Homeopatía en sí [...] es de gran complejidad y no ha habido en nuestro país médicos capacitados para ayudarnos en la primera etapa del aprendizaje. Felizmente [...] ya le es posible al médico comenzar el estudio de los grandes temas - Patología, Clínica y Terapéutica Homeopáticas - en la seguridad de que ha de encontrar quienes le faciliten el camino, le adviertan de los errores que suelen cometerse por desconocimiento de una técnica que es engorrosa ${ }^{50}$.

47 Estado financiero de la Sociedad Médica Homeopática Argentina (1935), Homeopatía, 2 (11-12), p. 330; Estado financiero de la Sociedad Médica Homeopática Argentina (1936), Homeopatía, 3 (10-11-12), p. 443. Los ingresos por cuota de los médicos también fluctúan de $\$ 1550$ (1935) a \$1390 (1936) hasta \$1616 (1938). Movimiento financiero de la Sociedad Médica Homeopática Argentina, Homeopatía, 5 (7-8), p. 222.

\footnotetext{
48 Editorial (1934a), Nuestro primer aniversario, Homeopatía, I (7), pp.197-198.

49 Editorial (1934a), p. 197.

50 EDITORIAL (1934a), p. 197.
} 
Una de las piezas que aquí se considera clave para entender este posicionamiento social es la narración de un mito fundacional que acompañe a este grupo emergente. Mircea Eliade distingue dos tipos de mito, el cosmogónico y el de origen: el primero da cuenta del «surgimiento del mundo» y el segundo es una prolongación del cosmogónico para explicar la aparición de fenómenos (que enriquecen y/o modifican aquel origen) e insertan en un sentido histórico más amplio los rituales actuales, en este sentido, Lévi Strauss habla de la irrupción del «otro tiempo» en el tiempo de los hombres.

Esto aparece bien claro en la segunda página del primer número de Homeopatia:

[La Homeopatía] había nacido bajo el cielo griego e Hipócrates, libre su espíritu de toda tradición, sin sugestiones pretéritas - no las tuvo porque vivió intelectualmente en el potencial mundo de lo increado - al formular el principio de la similitud, sentó las bases de la ciencia nueva.

Hay luego un largo interregno - la figura de Galeno se interpone para neutralizar las ideas del padre de la Medicina: otra vez griegos y latinos marcan su disidencia - hasta Paracelso que, con gesto de gigante, rompe las ataduras que amarraban las doctrinas médicas a la escolástica. Redescubre y comenta con intuición de iluminado el principio de la similitud. Enuncia posteriormente una verdad trascendental que recién en estos tiempos - iy han sido necesarios cuatro siglos! - recibe comprobación científica: el valor de la dosis infinitesimal, naturalmente expresado en una forma teórica y abstracta, a extremo de que fue materia de interpretaciones ocultistas $[\ldots]$

El siglo XVIII marca otro jalón en el desarrollo de la Homeopatía: interviene Hahnemann, sin duda alguna el creador de la técnica homeopática ${ }^{51}$.

Nótese que la serie de hitos históricos que se presentan como «homeopáticos» se cierra con Hahnemann, lo cual implica que el texto fue pensado (más allá de los guiños a los propios homeópatas) para un público más general, no homeópata, pero con algún conocimiento de historia general de la medicina. No obstante, la mínima mención sirve para ubicar en el corazón de la homeopatía al «creador de su técnica» cuya «obra es tan importante que, desde hoy, le dedicamos una sección preferente». Esto es importante destacarlo porque se publicaron posteriormente obras de Hahnemann y no así de Paracelso o Hipócrates (exceptuando eventuales citas), y si bien podría aducirse que estos autores eran leídos en las carreras de grado de medicina, es evidente que no se los leía con el prisma homeopático.

51 Semich, R. (1934a), Nuestros propósitos, Homeopatía, 1 (1), 2-3, p. 2. 
Lo que debe tomarse en cuenta aquí es que esta construcción de una genealogía, de un hilo metafísico ${ }^{52}$, que trasciende todas las épocas hasta llegar a la Grecia Antigua, lugar común de «cuna del pensamiento» y de Hipócrates, también lugar común del "padre de la medicina». Los términos empleados, además, dan cuenta de una narración mitológica: «había nacido bajo el cielo griego», le da a la disciplina una entidad sino corpórea, al menos espiritual; «libre su espíritu de toda tradición, sin sugestiones pretéritas», en oposición a la idea de que la homeopatía es un dogma, anclado en una tradición pseudocientífica, el hecho de fechar su nacimiento hasta donde pudiera tener referencias, es una manera de quitarle este estigma.

La oposición de griegos y latinos es una manera también de insertar a la disciplina en una problemática más general («otro tiempo» que no es el «tiempo de los hombres»), durante un período de tiempo en el que no hay referencias posibles, siguiendo con este interés de constituir a la homeopatía como una disciplina milenaria e «injustamente» marginada. De ahí que Lévi Strauss hable de los mitos como «maquinarias para destruir el tiempo», mediante un mecanismo por el cual las cosas del presente tuvieron un origen, al darle relevancia a aquello, lo que tiene pasado reclama en el presente una legitimación igual.

La aparición de Paracelso como redescubridor «con intuición de iluminado» del principio de similitud y de la dosis infinitesimal ${ }^{53}$, que «rompe las ataduras que amarraban las doctrinas médicas a la escolástica» en oposición a Galeno, un referente de la medicina alopática que los homeópatas también oponen a Hipócrates. Al mismo tiempo, marcando que las formulaciones teóricas de Paracelso fueron fruto de «interpretaciones ocultistas», distancia a la disciplina de posibles acusaciones de curanderismo, misticismo, etcétera, y pone de relieve nuevamente una cuestión «estructural»: de esta manera, como marca Lévi Strauss, la contingencia se resuelve subordinando la historia a la estructura $^{54}$. Por ejemplo, al citar una conferencia del médico español Grego-

52 En el sentido de la búsqueda de aquello que hay en común más allá de lo evidente. Expresado textualmente por Semich: «Esta rápida filiación histórica que dejamos hecha tiene un solo objeto: observar como, a través de tantas centurias, quedó siempre tendido un puente de enlace entre las ideas homeopáticas», SEMICH (1934a), p. 3.

53 Aclara Semich, además, que «Paracelso, médico, empleó siempre sus medicamentos a dosis débiles: hablaba corrientemente de una unidad, karenas, que definía diciendo que era la $24^{a}$ parte de una gota minúscula», SEMICH (1934a), p. 2.

54 Uno de los ejemplos que da Lévi Strauss: «otra finalidad consistía en emplear las tradiciones legendarias para fundamentar reivindicaciones contra los blancos -reivindicaciones territoriales, políticas y otras», LÉVI STRAUSS (1995), p. 59. 
rio Marañón, hacen alusión a esta cuestión: «Retomo en las páginas que siguen un viejo tema que, no obstante, para nuestro ambiente es nuevo» ${ }^{55}$.

En lo que podría entenderse como la misma línea «mítica», Jonás equipara el Organon de Hahnemann con el de Ariosto y Bacon ${ }^{56}$, de éste señala que en Instauratio Magna «muestra los vicios de la ciencia tal como se enseñaba desde muchos siglos atrás» y en Novum Organon «quería dar un instrumento nuevo [...] (con el cual) sacar la verdad científica o filosófica» considerándolo «una revolución contra la escuela de Aristóteles que dominaba en aquel entonces». Este es otro ejemplo en el que se puede establecer una clara conexión entre esta construcción discursiva y la formulación de los mitos en Lévi Strauss, pero en el cual se busca la legitimidad del Organon de Hahnemann, equiparándolo al de Bacon, asignándole similares valores y posición «revolucionaria».

De esta manera, el agrupamiento sería, por un lado Hipócrates, Paracelso y Hahnemann, junto con la «comprobación científica», «la ciencia nueva», «el espíritu libre» y, en definitiva, la propia Sociedad; por el otro, Galeno, las «ataduras de la escolástica», los alópatas y «las interpretaciones ocultistas». Este alineamiento puede entenderse como una manera de resolver esta «contingencia» (la de la aparición de una institución, la del hecho de que sea controvertida) por una «estructura» que divide en dos (alópatas y homeópatas; o el bien y el mal) la historia de la medicina.

No se debe perder de vista que desde el primer artículo del primer número de la revista, una suerte de carta de presentación al lector ideal (mediante un breve editorial en el que no se da cuenta de referencias bibliográficas) se plantea esta dicotomía rudimentaria que cobrará luego otras dimensiones, otro gradiente en el cual algunas cuestiones son negociables y otras no. En este sentido, tampoco se debe perder de vista la controversia que atraviesa este proceso y la asimetría de fuerzas entre un grupo y otro, de manera tal que la estructura dicotómica que plantean los homeópatas no es tal para los médicos «ortodoxos», como se ven en el texto de Belmartino y otros, el caso de la homeopatía no es siquiera mencionado.

55 Semich, R. (1934b), Una conferencia de Marañón en el congreso internacional de Homeopatía, Homeopatía, I (1), p. 8.

56 JonÁs, G. (1934b), La doctrina de la homeopatía, Homeopatía, I (1), p. 4. 


\section{LA MÍTICA ESTAMPA DE HAHNEMANN}

De un modo que refuerza la narrativa mítica fundante, la figura que representa Hahnemann para los editores de Homeopatía es central, hasta tal punto que merece inicialmente una serie de artículos dedicados sólo a reseñar su biografía. Esta descripción, bucólica, narra con exceso de detalles una vida iniciada «en la campiña» en una serie que tras tres capítulos, finalmente, acaba inconclusa ${ }^{57}$. Tómese el siguiente extracto a modo de ejemplo:

[a Hahnemann y sus hermanos] les enseñaron a escribir «jugando» como dice Hahnemann, y se esforzaron por elevar su espíritu sobre la común vulgaridad. El hijo rinde homenaje al padre que enseñaba a los suyos más por su ejemplo que con sus palabras y cuya divisa «Obrar y ser sin parecer» muestra una vida interior profunda y una voluntad de satisfacer, ante todo, su conciencia ${ }^{58}$.

Ya en el segundo artículo de la primera revista Homeopatía se inicia a los lectores en la doctrina homeopática, reproduciendola tal cual la expuso Hahnemann «poniendo a la luz de los conocimientos modernos de la medicina, en los comentarios que hagamos, una infinidad de hechos nuevos que la confirman, sin alterarla en lo más mínimo» ${ }^{59}$.

Esta voluntad iniciadora y didáctica trae consigo respectivas «traducciones» de la época y el lugar en que escribió Hahnemann a la realidad Argentina de la década de 1930 fijando, además, a quienes ya detentan en este espacio la autoridad para «comentar» su obra. La aclaración final del párrafo, comienza a indicar el carácter indiscutible e innegociable de los escritos del padre fundador: «Hahnemann posó los problemas filosóficos, patológicos, farmacológicos y terapéuticos y como consecuencia de ellos el surgimiento de la doctrina homeopática, única hasta la fecha, que está basada en leyes, que como la de gravitación, permanecerán inmutables» ${ }^{60}$.

Se podría pensar que, en algún sentido, se resquebraja la idea del mito fundacional que lleva los orígenes de la homeopatía hasta Hipócrates, pasando por Paracelso, en función de destacar lo «inédito» de la obra del padre fundador que a su vez resulta «inmutable». Sin embargo, vale recordar la idea

57 Croll PicArd (1934a), Hahnemann y la homeopatía, Homeopatía, I (1), pp. 13-15; Croll PiCARD (1934b), Hahnemann y la homeopatía, Homeopatía, I (2), pp. 50-51; Croll PICARD (1934c), Hahnemann y la Homeopatía, Homeopatía, I (4), p. 124-126.

58 CROLl PicARD (1934b), p. 50.

59 JONÁS (1934b), p. 4.

60 JONÁS (1934b), p. 4. 
de «sujetos escindidos» de Goffman y que ya la función de este artículo es «doctrinaria» y está dirigido a médicos que, si ya no están convencidos, al menos buscan un camino de inicio. No se supone la «escisión» como una estrategia consciente, sino como resultado de la implicación de los médicos con sus múltiples espacios sociales: aquí se pone de manifiesto la fascinación de la época por lo nuevo (lo nuevo viejo, en este caso, ya que se busca mantener la novedad de lo «único hasta la fecha»), en cierta medida solapado por la idea cientificista de «inmutabilidad» de las leyes científicas.

La legitimidad de su figura sobrepasa por momentos los méritos científicos y se asienta sobre el carácter loable de su empresa: «La obra de Hahnemann no sólo tiene elevada significación intelectual, sino que marca nobles normas éticas. Su vida misma fue ejemplar y heroica [...] Prefiere las horas dolorosas y acres de la voluntaria pobreza que vendrá a los halagos de la fortuna que ya conoció en días brillantes y triunfales» ${ }^{61}$.

La figura del fundador de la doctrina, reúne todas las bondades de la terapéutica («observación», «experiencia», «razón») que viene a salvar la ética del médico con la premisa de «curar, ante todo»:

Hahnemann fue un revolucionario en medicina, eso a nadie le cabe duda, pero al mismo tiempo enseñó a sus discípulos a hacer uso de la observación, la experiencia y la razón, en el difícil arte de curar. Colocó en primer término el problema médico, la curación de las enfermedades. Es indudable que para esto es necesario, conocer los factores que entran en juego, enfermedad, medicamento y manera de emplearlo terapéuticamente.

La armonía de estos tres términos no pudo ni debió ser alterada jamás, como ocurrió entonces y ha seguido ocurriendo hasta la fecha. Si uno de los tres factores hace un desarrollo muy grande en detrimento de los otros, resulta que se rompe el equilibrio y entonces ninguno de los tres tiene utilidad práctica ${ }^{62}$.

Respecto a esta premisa de «la cura ante todo», tan presente en el discurso médico de la época, difícil discernir hasta qué punto forma parte de la implicación de la propia homeopatía o más bien una adaptación a la problemática general de aquellos tiempos, o una combinación de ambas, según el cual la homeopatía sería per se una disciplina cuyos representantes la sostienen adaptándose a la problemática de la época ${ }^{63}$.

61 SEmich, R. (1934c), En el Aniversario de Hahnemann, Homeopatía, I (4), 99-103, p. 102.

62 JONÁS (1934b), p. 4.

63 Este argumento representa la hipótesis de Olivier Faure (FAURE, O. (2002/3), L'homéopathie entre contestation et integration. En Actes de la recherché en sciences socia- 
En todo caso, el rol central de la cuestión de la curación juega un papel preponderante en los artículos de Homeopatía y en el propio subtítulo de la obra capital de Hahnemann: el Organon o el Arte de Curar. Ésta obra constituye un punto de referencia ineludible a lo que fue la experimentación en esta disciplina y a lo que fue y es la base de la terapéutica. Es el punto de partida «científico» de los principios que rigen la disciplina:

El nombre de Organon que puso Hahnemann a su obra capital, indica desde ya, que esta obra no es un tratado dogmático y menos didáctico, sino que se trata de una lógica de la medicina. En efecto, en él no se hace prevalecer una idea concebida a priori sino de dar a quienes se ocupan de curar, un instrumento, un método, o recurso, para dirigirlos en la parte más difícil de su misión, que es aliviar y curar enfermos ${ }^{64}$.

Como se ve, se plantea la diferenciación de «ideas preconcebidas» $\mathrm{y}$ «dogmáticas», contra las críticas que arreciaban calificando de esta manera a la disciplina, aunque a la vez se ponía de manifiesto el carácter «inmutable» de las leyes que había «descubierto» Hahnemann. También aparece, por un lado, el carácter instrumental del Organon y, por otro, un cariz no «didáctico» sino «lógico», lo cual da como resultado una serie de premisas que pueden servir para la curación en tanto se haga una lectura correcta de las mismas.

Inclusive cada opinión favorable de otros autores no homeópatas, es moilizada para reivindicar al «Maestro». Utilizan, por ejemplo, el comentario del médico «alópata» español Gregorio Marañón quien en un congreso de homeopatía en Madrid afirmó que «Hahnemann tuvo atisbos geniales y que fue el precursor de los avances más importantes de la terapéutica actual» ${ }^{65}$.

Seguidamente, el representante homeópata convierte el comentario de «atisbos geniales» a la afirmación de que «Hahnemann fue un hombre genial», el peso de lo «extraordinario», puesto por Marañón en determinadas acciones de Hahneman, es trasladado por Semich al propio Hahneman, resaltando la exaltación del padre fundador como núcleo duro del imaginario homeopático.

En el primer año de publicación de Homeopatía se recuerda el aniversario del natalicio de Hahnemann con un breve artículo en el que «obligadamente»

les, 143, pp. 88-96), para quien la homeopatía combina argumentos combativos y adaptados a la época, lo cual (desde el punto de vista que se considera válido desde este trabajo) parece violar el argumento de simetría planteado por Bloor (BLOOR, D. (1998), Conocimiento e imaginario social, Barcelona, Gedisa), ya que no parece considerar al menos que el resto del conocimiento médico también puede ser considerado de igual manera.

64 JONÁs (1934b), p. 4.

65 SEMICH (1934b), p. 12. 
se lo homenajea en virtud de «su vida y su obra tan ricas en heroísmo y genialidad». Las ideas y prácticas hahnemannianas se «consagran como verdad probada» y «día a día se extienden por el mundo civilizado en razón de su poder lógico y su eficacia terapéutica» ${ }^{66}$.

Esta consagración, por cierto, aparece como una verdad autoevidente ante el «progreso de la medicina» y no ante la ponderación de otros factores. En este homenaje se pondera a Hahnemann como el creador del método experimental, contraponiéndolo a las figuras que enarbolaban los médicos «alópatas»:

Consideremos que aún no habían surgido Pasteur ni Claudio Bernard, pero Hahmenann ya había hecho experiencias en el hombre. Hahnemann, para todo médico sin prejuicios y que conozca la historia de la medicina, es el verdadero fundador del método experimental. Este, pues, es otro título que le corresponde con toda legitimidad.

Hahnemann no se limitó a ser un experimentador original y sagaz; fue mucho más que eso: fue un gran médico. Indicó directivas clínicas y terapéuticas, muchas de las cuales hoy podemos seguir al pie de la letra en nuestra práctica, en la seguridad de ser eficaces a los enfermos. Así, todos los colegas debieran leer el «Organon» y meditar seriamente acerca de las grandes orientaciones que da esta obra magistral, verdadera biblia del médico ${ }^{67}$.

Dos años después, el 14 de abril de 1936, se conmemora el $181^{\circ}$ aniversario del nacimiento de Hahnemann con un «banquete» en el Alvear Palace Hotel, «una simpática demostración de camaradería, donde se advirtió, una vez más, cómo los médicos homeópatas han sabido constituir y dar vida propia, en breve tiempo, a la institución tutelar que los reúne» ${ }^{68}$. Cabe recordar que en esta fecha siquiera habían pasado dos años de la primera reunión de julio de 1934, y cómo a través de la conmemoración de Hahnemann se busca reivindicar la «institución tutelar» y a sus miembros, haciendo especial hincapié en el escalafón de la Sociedad.

En la revista se publica en forma íntegra un discurso pronunciado por el presidente de la Sociedad, Godofredo Jonás, quien destaca aquella como la vez primera que se homenajea al «médico, el filósofo, el químico lleno de sabiduría, el políglota que llenó con sus traducciones científicas anaqueles

66 SEMICH (1934c), p. 99.

67 SEMICH (1934c), p. 102.

68 Editorial (1936), Conmemoración del $181^{\circ}$ aniversario del nacimiento de Hahnemann, Homeopatía, 3 (5), pp. 117-120. 
enteros, nuestro inmortal Hahnemann, que arrancó a la naturaleza la "ley de los semejantes" y de las "dosis infinitesimales" $\rangle^{69}$.

Aquí la puesta en juego de la figura del padre fundador, figura mítica que sirve como reivindicación de la terapéutica homeopática, basada según se muestra en un ser «inmortal», capaz de hazañas tales como «arrancar leyes a la naturaleza», «llenar bibliotecas», «dominar distintas artes y ciencias»... La otra función es la de resaltar el lugar en la historia de los miembros, consiguiendo en algún sentido ser «pioneros» en el país, reservándose para sí un lugar destacado en aquel hilo metafísico de los grandes de la medicina.

Posteriormente, Jonás destaca que el padre fundador creó una terapéutica «para bien de la humanidad» sobre «el principio más humano que haya podido concebir la medicina hasta el presente, como es el de la experimentación de los medicamentos en el hombre sano», con el objetivo de «terminar con una terapéutica antirracional, anticientífica e infusa [...] que para desdicha de la humanidad todavía persiste, aunque debatiéndose en una confusión terrible, que vislumbra su estrepitoso derrumbe $\rangle^{70}$. Aquí se percibe más claramente el juego entre el pasado y el presente, la cuestión estructural que signó la época de Hahnemann y perdura en la lucha entre los homeópatas de hoy, quienes serán los sepultureros de lo «antirracional» y «anticientíficos».

Así, explicando que «prefiere» no ahondar en la «grandeza [que] impide abreviar» del padre fundador, el presidente de la Sociedad sigue su disertación refiriéndose a los «logros de la homeopatía» en Argentina, básicamente ligados a la pelea contra los «intereses creados» de la «ciencia médica oficial», apoyada por el éxito de sus curaciones ${ }^{71}$.

Al año siguiente, se vuelve a realizar una reunión en la que Jonás «ofreció la comida en un galano discurso, haciendo resaltar la personalidad de Hahnemann y los beneficios que produce a la humanidad la Homeopatía» y de la que los médicos salieron «satisfechos, pensando cada día ser más homeópatas y luchar con entusiasmo por la expansión de la doctrina» ${ }^{72}$.

En el mismo número de abril de 1937 en el que se publica la breve misiva sobre el segundo «banquete» aparece también un editorial que hace referencia al natalicio de Hahnemann como «aniversario fausto del glorioso genio». Allí

\footnotetext{
69 EDITORIAL (1936), p. 117.

70 EditORIAL (1936), p. 117.

71 EDITORIAL (1936), p. 118.

72 Edtorial (1937b), Banquete ofrecido por la Sociedad Homeopática Argentina con motivo del 182 aniversario del nacimiento de Christian Federico Samuel Hahnemann, Homeopatía, 4 (3-4), p. 51.
} 
se alude al padre de la homeopatía como quien «aprendió la medicina de entonces, agotando todos los conocimientos, hasta que, desilusionado de la terapéutica, cerró su consultorio médico porque no podía, de acuerdo con su moral, dar a los enfermos lo que le pedían: la salud» ${ }^{73}$.

En el citado editorial se da una explicación acerca de cómo Hahnemann «descubrió» la terapéutica que lo haría famoso. Aquel creador de poderes ilimitados, entonces, vivió el mismo desaliento que todos los médicos de la década de 1930:

No consolándose con que el Divino Creador hubiera puesto a la criatura humana en tan precarias condiciones en el mundo, vióse un día iluminado por esa luz que sólo sabe percibir el genio, y llegó a su inteligencia la causa única y verdadera por la cual los medicamentos pueden ser eficaces. Esta revelación la tradujo en palabras, diciendo que: los medicamentos sólo curan las enfermedades o los síntomas que ellos son capaces de producir en el hombre sano [...] Constituye esto la única ley sobre la que se basa la curación y [...] ningún agente medicamentoso es capaz de curar nada si no actúa de acuerdo esta ley ${ }^{74}$.

De Dios a Hahnemann ${ }^{75}$, de éste a la SMHA, de allí a la farmacia y a su casa, el milagro homeopático no sólo logra curar, sino que además hace que sus defensores se sientan «fuertes» y «confiados» para seguir las huellas de esta «revelación [que] puso a Hahnemann sobre el camino de la verdadera ciencia de curar». Tal acto de fe, supuso el ofrecimiento sacramental de «mil francos» enviados a «la Societé Homéopathique Française, para que sirvan a la conservación del mausoleo que en el cementerio de Père Lachaise guarda sus restos» ${ }^{76}$.

Lo que cabe destacar, entonces, es cómo esta figura central del padre fundador opera como elemento de cohesión último e indiscutible, favoreciendo reuniones rituales en las que se reivindica su imagen, pero sobre todo se da

73 Editorial (1937c), 10 de abril de 1755-1937. Fecha gloriosa de la Homeopatía, Homeopatia, 4 (3-4), pp. 49-50.

74 Editorial (1937b), p. 49-50.

75 Como epígrafe de una fotografía de la tumba de Hahnemann se indica: «El Divino Fundador de la Homeopatía, Samuel Hahnemann, falleció en París, en plena Gloria, en el año 1843» (DEVEZE (1936), p. 345).

76 EditORial (1937b), p. 50. Ya en 1935 el presidente de la SMHA, Godofredo Jonás (en el viaje que hizo al congreso de homeopatía de Budapest), de paso por París rindió «un homenaje ante la tumba de Hahnemann», acto que consta en una fotografía en la que se puede ver al médico argentino y una ofrenda floral junto a la tumba (Homenaje de los Médicos Homeópatas Argentinos (1935), Homeopatía, 2 (9-10), p. 260). 
espacio a los médicos locales para poner en juego socialmente su escalafón. Esta jerarquización es transmitida mediante las revistas por canje, acto consolidado a nivel internacional por el donativo y la pompa de las reuniones, como reaseguro de que esta legitimación se sostenga de modo más amplio.

Además, hacia el naciente grupo de homeópatas de la SMHA funciona como una figura a seguir, una representación perfecta de la puesta en acto de los médicos homeópatas de la década de 1930, denodados luchadores propios de una época «rebelde», que en todo se parece pero en algo se distingue de todas las anteriores luchas del «bien» contra el «mal»: esta vez el triunfo del «bien» es inminente e ineluctable.

Hahnemann, como todos los grandes innovadores, fue combatido acerbamente; se usaron contra él todas las armas, incluso la calumnia y la injuria. Se vociferaba contra la Homeopatía tachándola de embuste y engaño vil. Pero en tanto la sabiduría oficial se debatía en su impotencia frente a los enfermos, Hahnemann los curaba. Aún después de desaparecido de este mundo aquel hombre extraordinario, no cesó la campaña hostil y hasta hace algunos años ser médico homeópata y defender las ideas hahnemannianas significaba ofrecer cómodo blanco para las burlas sangrientas de los colegas y del público.

Esta situación injusta ha terminado en forma definitiva. En nuestra época - tan impregnada de rebeldía y obligadamente revisionista de los errores cometidos - la medicina tiende a una evolución fatal que la lleva a modificar de raíz sus principios y sus métodos. Y tal modificación tiene ya un perfil inconfundible por lo bien delineado, y, por ello, de fácil identificación: las ideas científicas que la nutren son de indiscutible filiación homeopática ${ }^{77}$.

\section{CONCLUSIONES}

En los apartados sobre la construcción del mito fundacional y la figura mítica de Hahnemann se puede observar cómo las caracterizaciones de Eliade coinciden en la narración homeopática analizada: presentan la historia de la homeopatía y de Hahnemann como la historia «sagrada» que irrumpe de manera dramática en el mundo, enmarcada en el relato de una historia más general que explica los acontecimientos primordiales a partir de los cuales el hombre (médico) ha llegado a ser lo que es hoy. Tanto la historia de la disciplina como las intervenciones de su fundador son de una naturaleza «verdadera» per se, que se convierte en el modelo ejemplar de todas las actividades

77 Semich (1934c), p. 103. 
significativas. Además, hay una explícita voluntad de crear los medios de comunicación (reuniones, revistas) que canalizarán este mito y garantizarán su «reactualización»a los neófitos durante su iniciación.

No es posible establecer si esta estructura de canalización de símbolos y significados es inherente a la práctica homeopática, lo que sí se muestra en los distintos trabajos citados sobre el ideario e imaginario de la época es una particular fertilidad para este tipo de construcciones, cuasi mitológicas, legitimadas más bien por un descreimiento hacia el saber establecido de corte positivista, más que la construcción de nueva evidencia propia. Si el saber establecido tambaleaba, la creencia sobre ciertos fenómenos antes denostados por ese saber recobraba fuerza, impulsados, a su vez, por los prodigios técnicos que hacían posibles fenómenos imaginados. Como si esto fuera poco, la homeopatía resurgía con ímpetu en Francia, con lo cual los rituales vernáculos recibían un espaldarazo por la cultura más admirada en la sociedad porteña.

La revista Homeopatía refleja el esfuerzo explícito de los médicos homeópatas por construir legitimidad para la institución naciente a partir de la construcción de ciertos relatos, entre los cuales se destacan los expuestos en éste artículo. La batalla discursiva y legal que da comienzo con estos incipientes intentos de legitimación, deriva pocos años después, en 1940, en el reconocimiento jurídico de la institución, sin que hubiera de por medio ningún tipo de construcción de «nueva evidencia».

Fecha de recepción: 16 de octubre de 2008

Fecha de aceptación: 15 de junio de 2009 